\title{
Open-access colonoscopy in Ontario: Associated factors and quality
}

\author{
Shane Hadlock MD FRCPC ${ }^{1}$, Linda Rabeneck MD MPH FRCPC ${ }^{2,3}$, Lawrence F Paszat MD MSC FRCPC ${ }^{3}$, \\ Rinku Sutradhar $\mathrm{PhD}^{3,4}$, Andrew S Wilton $\mathrm{MSC}^{3}$, Jill Tinmouth MD PhD FRCPC ${ }^{3,5}$
}

\begin{abstract}
S Hadlock, L Rabeneck, LF Paszat, R Sutradhar, AS Wilton, J Tinmouth. Open-access colonoscopy in Ontario: Associated factors and quality. Can J Gastroenterol 2013;27(6):341-346.
\end{abstract}

BACKGROUND: Open-access (OA) colonoscopy may increase efficiency and decrease wait times; however, because the patient is seen for the first time at the endoscopy appointment, previous processes, such as information about the procedure, preparation and appropriate triage, may be suboptimal.

OBJECTIVE: To identify factors associated with OA colonoscopy and to determine the relationship between OA colonoscopy and an important quality measure, incomplete colonoscopy.

METHODS: A population-based analysis of all adult outpatients undergoing a first-time colonoscopy between 1997 and 2007 in Ontario was performed. Colonoscopy was considered to be OA if there were no visits in the preceding five years with the physician performing the colonoscopy. Using logistic regression, patient, physician and institution factors associated with OA colonoscopy were identified. Using propensity score matching, the relationship between $\mathrm{OA}$ colonoscopy and incomplete colonoscopy in 2006 was examined.

RESULTS: A total of 1,079,259 colonoscopies were performed. Of these, $14 \%$ were OA in 1997 compared with $26 \%$ in 2007. Patients 50 to 69 years of age, those from higher-income neighbourhoods and those with less comorbidity were more likely to undergo OA colonoscopy. The odds of receiving OA colonoscopy were six times greater in a nonhospital clinic compared with a community hospital. Colonoscopy was more likely to be complete if the procedure was OA (OR 1.3 [95\% CI 1.2 to 1.4$] ; \mathrm{P}<0.0001)$.

CONCLUSIONS: Rates of OA colonoscopy have increased substantially since 1997. Institution type was most strongly associated with OA colonoscopy. Colonoscopy completeness, a recognized quality indicator, does not appear to be compromised by OA colonoscopy.

Key Words: Ontario; Open-access colonoscopy; Population-based studies

pen-access (OA) colonoscopy is the provision of colonoscopy without previous clinical consultation (1); as such, patients do not meet with the endoscopist for clinical evaluation and discussion before the scheduled procedure date. OA colonoscopy is being used with increasing frequency in the United States and Europe $(2,3)$. In Ontario, the decision to perform OA colonoscopy is left to the discretion of the endoscopist because few formal OA scheduling models exist. Previous studies from the United States and Italy have evaluated OA colonoscopy for the appropriateness of indication and referral criteria, detection of significant disease and quality (4-6). In the 1990s, a single study surveyed 1500 American endoscopists with respect to their use of OA colonoscopy (3). To our knowledge, there are no population-based studies reporting on the utilization of OA colonoscopy - specifically, there are no studies evaluating the prevalence of and factors associated with the provision of OA colonoscopy.

\section{La coloscopie en accès ouvert en Ontario : des facteurs connexes et la qualité}

HISTORIQUE : La coloscopie en accès ouvert (AO) peut accroître l'efficacité et réduire les temps d'attente. Cependant, puisque le patient est vu pour la première fois lors du rendez-vous d'endoscopie, les processus antérieurs, tels que la prise d'information, la préparation et le triage pertinent, peuvent être sous-optimaux.

OBJECTIFS : Déterminer les facteurs liés à la coloscopie en $\mathrm{AO}$ ainsi que le lien entre ce type de coloscopie et une coloscopie incomplète, qui constitue une mesure importante de la qualité.

MÉTHODOLOGIE : Les chercheurs ont procédé à une analyse en population de tous les patients adultes en consultations externes ayant subi une première coloscopie en Ontario entre 1997 et 2007. La coloscopie était considérée comme en $\mathrm{AO}$ si le patient n'avait pas eu de rendez-vous avec le médecin ayant exécuté la coloscopie dans les cinq années précédentes. Au moyen de la régression logistique, les chercheurs ont déterminé les facteurs liés au patient, au médecin et à l'établissement relatifs à cette coloscopie. Au moyen de l'appariement des coefficients de propension, ils ont examiné le lien entre la coloscopie en $\mathrm{AO}$ et la coloscopie incomplète en 2006.

RÉSULTATS : Au total, 1079259 coloscopies ont été exécutées. De ce nombre, 14 \% étaient en AO en 1997, par rapport à $26 \%$ en 2007. Les patients de 50 à 69 ans, ceux de quartiers plus aisés et ceux dont la comorbidité était moins élevée étaient plus susceptibles de subir une coloscopie en AO. La chance de subir ce type de coloscopie était six fois plus élevée dans une clinique non hospitalière que dans un hôpital général. La coloscopie était plus susceptible d'être complète si elle était en $\mathrm{AO}$ (RRR 1,3 [95 \% IC 1,2 à 1,4]; P<0,0001).

CONCLUSIONS : Les taux de coloscopies en $\mathrm{AO}$ ont considérablement augmenté depuis 1997. Le type d'établissement s'associait le plus à ce type de coloscopie. La coloscopie complétée, un indicateur de qualité reconnu, ne semble pas être compromise par la coloscopie en AO.

With the increasing demand for endoscopic procedures, the potential advantages of $\mathrm{OA}$ scheduling models include reduced wait times, lower costs and improved efficiency. Disadvantages include inappropriate indication (5) and suboptimal preprocedure risk assessment (7), as well as the possibility that patients do not receive adequate informed consent before the procedure. There is also evidence to suggest that patients undergoing $\mathrm{OA}$ procedures may be less well informed about their procedure than those seen by the endoscopist before the procedure (8). We hypothesized that if patients receiving OA colonoscopy are poorly informed about their procedure, they may experience higher rates of incomplete colonoscopies as a result of poor bowel preparation compared with those who see a physician before the procedure.

We performed two population-based cohort studies using health administrative databases from Ontario, between April 1, 1997, and March 31, 2007. Our primary objectives were to measure the utilization

${ }^{1}$ Department of Medicine, Division of Gastroenterology, University of Ottawa, Ottawa; ${ }^{2}$ ancer Care Ontario, ${ }^{3}$ Institute for Clinical Evaluative Sciences,

University of Toronto; ${ }^{4}$ Department of Biostatistics, Dalla Lana School of Public Health, University of Toronto; ${ }^{5}$ Department of Medicine, Division of

Gastroenterology, Sunnybrook Health Sciences Centre, Toronto, Ontario

Correspondence: Dr Jill Tinmouth, Department of Medicine, Division of Gastroenterology, Sunnybrook Health Sciences Centre,

2075 Bayview Avenue, Room HG40, Toronto, Ontario M4N 3M5. Telephone 416-480-5910, fax 416-480-4845, e-mail jill.tinmouth@sunnybrook.ca Received for publication January 7, 2013. Accepted January 30, 2013 


\begin{tabular}{|c|c|c|}
\hline $\begin{array}{l}\text { Endoscopy-related } \\
\text { definitions }\end{array}$ & Database & Codes \\
\hline Colonoscopy & OHIP & \\
\hline To descending colon & & Z555 \\
\hline To splenic flexure & & $Z 555+E 740$ \\
\hline To hepatic flexure & & $Z 555 \pm E 740+E 741$ \\
\hline To cecum & & $\mathrm{Z} 555 \pm E 740 \pm E 741+E 747$ \\
\hline To terminal ileum & & $\mathrm{Z} 555 \pm \mathrm{E} 740 \pm \mathrm{E} 741 \pm \mathrm{E} 747+\mathrm{E} 705$ \\
\hline $\begin{array}{l}\text { Positive colonoscopy } \\
\text { findings }\end{array}$ & $\mathrm{OHIP}$ & $\begin{array}{l}\text { Z555 and 1+ of the following: Z570, E719, } \\
\text { Z571, E720, Z764, Z765, E687, E685, } \\
\text { E717, E785 }\end{array}$ \\
\hline $\begin{array}{l}\text { Negative colonoscopy } \\
\text { findings }\end{array}$ & $\mathrm{OHIP}$ & $\begin{array}{l}\text { Z555 without codes listed above } \\
\text { representing biopsy, polyp/tumour removal }\end{array}$ \\
\hline $\begin{array}{l}\text { Diagnosis of colorectal } \\
\text { cancer }\end{array}$ & OCR & $\begin{array}{l}153.0 \text { to } 153.9 \text { inclusive, excepting } 153.5 \\
\text { (appendix), } 154.0,154.1 \text { or } 154.8\end{array}$ \\
\hline EGD & OHIP & Z515, Z399, Z400, Z527, Z547 \\
\hline
\end{tabular}

EGD Esophagoduodenoscopy; OCR Ontario Cancer Registry; OHIP Ontario Health Insurance Plan

of OA colonoscopy over the 10-year study period and to identify patient, physician and institutional factors associated with this practice; and to determine if there is an association between OA colonoscopy and incomplete colonoscopy.

\section{METHODS}

Ethics

The Research Ethics Board at the Sunnybrook Health Sciences Centre (Toronto, Ontario) approved the study.

\section{Data sources}

The study was conducted at the Institute for Clinical Evaluative Sciences (Toronto, Ontario), which houses the health records of all residents of Ontario. These records are housed in administrative databases that are linked by an encrypted version of each resident's provincial health plan number.

For the present study, the following databases were used: Canadian Institute for Health Information (CIHI) Discharge Abstract Database (CIHI-DAD) and Same Day Surgery (CIHI-SDS), the Ontario Health Insurance Plan (OHIP), the Registered Persons Database and the Institute for Clinical Evaluative Sciences Physician Database (IPDB). The CIHI databases contain clinical, demographic and administrative data for all hospital discharges (DAD) and for same-day procedures including endoscopy since April 1, 1988. OHIP holds physician billing claims for services including procedures and consultation visits since July 1, 1991. The Registered Persons Database has maintained age, sex, postal code information and vital statistics for all Ontario residents with a valid OHIP number since 1991 . The IPDB provides physician specialty.

\section{Overview}

Two related population-based cohort studies were performed: a study to identify patient, physician and institutional factors associated with the receipt of OA colonoscopy; and a study to determine whether OA colonoscopy and incomplete colonoscopy are associated. For the first study, a population comprising all adult patients who underwent a first-time outpatient colonoscopy in Ontario between April 1, 1997 and March 31, 2007, was considered; the analysis of associated factors was restricted to the final fiscal year (FY) in this time period. The second study identified all adult patients undergoing a first-time outpatient OA colonoscopy between April 1, 2006 and March 31, 2007 (ie, FY 2006) and matched them using propensity scores to patients undergoing non-OA outpatient colonoscopy in the same time period. Study 1 cohort - predictors of OA colonoscopy: Using the OHIP database, all adults $>18$ years of age who underwent a first-time outpatient colonoscopy in Ontario between April 1, 1997 and March 31, 2007, were identified. Colonoscopy was defined as the insertion of the colonoscope to or beyond the splenic flexure (OHIP codes Z555+E740 \pm others that were used) based on the OHIP fee codes (Table 1) billed by the endoscopist performing the procedure. There is a separate OHIP fee code for flexible sigmoidoscopy (Z580); therefore, the definition should have captured all colonoscopies performed in Ontario during the period in question. Patients undergoing a first-time colonoscopy were defined as those without any OHIP billings for colonoscopy in the five years before the date of the procedure. Outpatients comprised individuals who underwent procedures without an overlapping hospital admission in CIHI-DAD, which would denote inpatient status, on the day of the procedure.

Because OHIP claims data were used to identify endoscopic procedures, including regions with non-fee-for-service reimbursement arrangements, it could have led to underestimates in the analysis. Specialist physicians in Kingston (South East Academic Medical Organization) and some general surgeons performing endoscopy in the North West district (Kenora, Rainy River, Ontario) have negotiated alternative funding arrangements with the Ontario Ministry of Health and Long-Term Care. Accordingly, patients living in the Southeast (Kingston) and Northwest (Rainy River and Kenora districts) health regions were excluded from the study.

Study 2 cohort - association between OA and incomplete colonoscopy: Using a similar strategy to that outlined above, all adults undergoing a first-time outpatient colonoscopy in FY 2006 were identified. Once again, patients living in the Southeast and Northwest health regions were excluded from the cohort.

\section{Definitions and factors examined}

OA and non-OA colonoscopy: Patients undergoing OA colonoscopy were defined as those without a documented consultation (OHIP billing codes with prefixes $\mathrm{A}$ or $\mathrm{C}$ ) or procedure visit (OHIP billing codes with prefixes $\mathrm{E}, \mathrm{G}, \mathrm{S}$ or Z) with the physician performing the colonoscopy in the five years before the date of the colonoscopy. Patients were classified as having undergone a non-OA colonoscopy if they had a documented consultation or procedure visit with the physician performing the colonoscopy within five years of the date of the colonoscopy.

Complete and incomplete colonoscopy: Using OHIP procedure codes, colonoscopy was considered complete if the endoscopist reached the cecum or terminal ileum, while incomplete colonoscopy comprised the remaining procedures (Table 1).

Patient factors: At the date of colonoscopy, data regarding patient age, sex, comorbidity, urban/rural status, health region and median neighbourhood income quintile were collected. Comorbidity was measured using the validated Johns Hopkins Case-Mix System (9-11). Ontario inpatient (CIHI) and outpatient (OHIP) diagnosis codes from the year before colonoscopy were used to estimate case-mix using the Johns Hopkins algorithm. Specifically, comorbidity was adjusted for using aggregated diagnosis groups, which are clinically meaningful groupings of diagnoses that are similar in terms of disease severity and anticipated duration. Comorbidity was categorized by the number of aggregated diagnosis groups ( 0 to 3,4 to 5,6 to 7 , and 8 or more). This comorbidity measure was selected because it was more appropriate for an outpatient cohort and because it minimized missing data when compared with another commonly used measure, the Deyo adaptation of the Charlson score (12), which relies on inpatient diagnosis codes only.

Using residential postal code, each patient was assigned to one of the province's 14 health regions. The health regions, known as local health integration networks, are not-for-profit corporations that are responsible for planning, integrating and funding local health services within specific geographical areas (www.lhin.on.ca).

Urban and rural status was determined using the Statistics Canada definition, which designates census metropolitan areas with a population of at least 10,000 as urban and all other census metropolitan areas 
as rural. Median annual neighbourhood household income at the level of the enumeration area, obtained from Statistics Canada, was linked to patient postal code. This strategy has been used by others to impute socioeconomic status $(13,14)$.

Physician factors: Physician specialty was categorized as gastroenterology, surgery, internal medicine and 'other practitioners'. The 'other practitioner' category comprised all other specialties including family physicians and general practitioners. For each year of the study, physicians were assigned to colonoscopy volume quintiles based on the mean annual number of colonoscopies performed in the preceding five years.

Institutional factors: Colonoscopy setting was classified as hospital, nonhospital or not classifiable (15). Hospital setting was further divided into academic or community. Colonoscopies were considered to be hospital-based if there was a CIHI-SDS record and nonhospitalbased if OHIP code E749 (for colonoscopies performed outside of hospitals) was billed without an overlapping CIHI record. Those considered 'not classifiable' had no CIHI record and the E749 code was not billed.

Endoscopy-related factors: Endoscopy characteristics, including positive and negative findings on colonoscopy, diagnosis of colorectal cancer (CRC) at colonoscopy and patients undergoing concomitant esophagogastroscopy, were recorded. Colonoscopy findings were classified as 'positive' if a biopsy or polyp removal was performed on the day of the colonoscopy, or if a second colonoscopy with biopsy or polyp removal was performed within six months of the initial procedure (ie, intended to capture a repeat colonoscopy for removal of an endoscopic lesion detected at the initial colonoscopy) (16). All remaining colonoscopies were considered to be 'negative'. Patients who had CRC diagnosed at colonoscopy were defined as those whose date of cancer diagnosis occurred on the day of the procedure or within a six-month period following the initial colonoscopy (16).

In the non-OA group, wait time from the date of the endoscopist consultation to the colonoscopy was determined. The wait times were then classified into one of four groups: one to 90 days; 91 to 180 days; 181 to 365 days; and $>365$ days. By definition, it was not possible to calculate wait time in a similar fashion for OA procedures because there was no preceding endoscopist consultation. Because the family physician visit that triggered the referral to the endoscopist using the administrative data could not be identified, it was not possible to determine the wait time from family physician referral to colonoscopy.

\section{Analysis}

Statistical analyses were conducted using SAS version 9 (SAS Institute, USA) and R (17).

Study 1: The number of first-time outpatient OA and non-OA colonoscopies per FY was determined over the study period. Patient, physician, institutional and endoscopy-related factors are reported by receipt of $\mathrm{OA}$ and non-OA colonoscopy. Univariate analyses using $\chi^{2}$ testing were performed to compare differences in patient, physician, institution and endoscopy-related factors for OA and non-OA procedures. Multivariate logistic regression modelling was used to identify patient, physician and institutional factors associated with the use of OA colonoscopy in FY 2006. To account for potential clustering of patients within physicians, a generalized estimating equations approach was used initially; however, this model did not converge using SAS or R. Thus, a logistic regression was used as the final model.

Study 2: The exposure was receipt of OA colonoscopy while the outcome was colonoscopy completeness. Propensity score matching was used in the analyses $(18,19)$ to balance the distribution of possible observed confounders between patients receiving versus not receiving OA colonoscopy. The propensity score is the subject's probability of being exposed (ie, receiving OA colonoscopy), conditional on measured covariates; it is derived from his or her covariate information. A propensity score model was constructed using patient (income quintile, health region, comorbidity), physician (annual colonoscopy volume, specialty) and institution factors (facility type) to model the

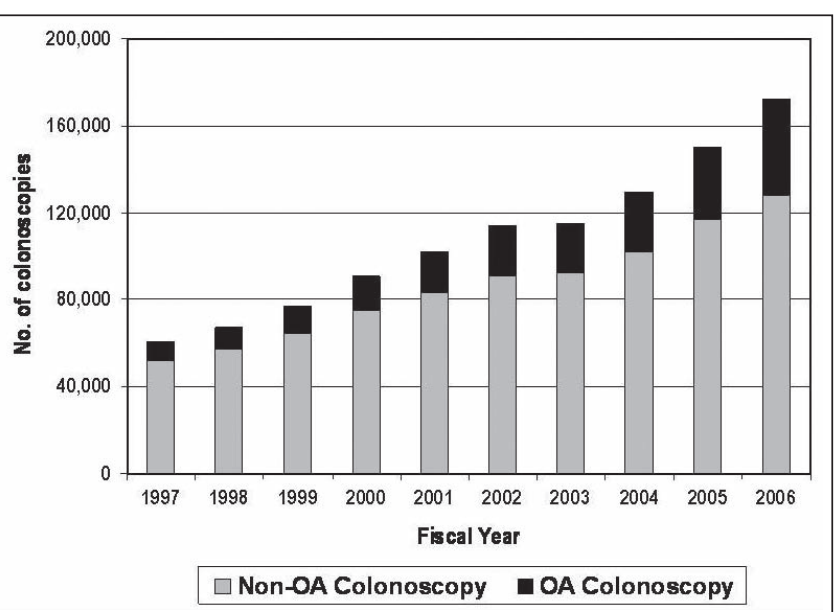

Figure 1) The number (No) of first-time open-access (OA) and non-OA colonoscopies according to fiscal year in Ontario (1997 to 2006)

probability of receipt of OA colonoscopy. Using these scores, individuals who received OA colonoscopy in FY 2006 were matched to those who did not on a 1:1 ratio using age, sex and the propensity score. These matched patients were followed forward to determine the outcome. Using conditional logistic regression to account for the matched design, the association between $\mathrm{OA}$ colonoscopy and incomplete colonoscopy was determined.

\section{RESULTS}

A total of 1,079,259 first-time outpatient colonoscopies from April 1, 1997 to March 31, 2007, in Ontario were identified. Of these, $216,413(20 \%)$ were OA. The total number of first-time outpatient colonoscopies significantly increased from 60,649 in 1997 to 172,158 in 2006 with the proportion of OA colonoscopies increasing from $14 \%$ in FY 1997 to 26\% in FY 2006 (Figure 1).

\section{Study 1}

Patient and physician characteristics of the study cohort are summarized in Table 2 . The proportion of patients with positive endoscopic findings (36\% of OA and $38 \%$ of non-OA colonoscopies) and in whom CRC was diagnosed ( $2 \%$ in each group) was similar between the two groups. In the non-OA colonoscopy group, the median wait time was 36 days (interquartile range 16 to 73 days). In FY 2006, onehalf of all OA colonoscopies in Ontario were performed in nonhospital settings (Table 3). The proportion of all first-time outpatient colonoscopies that were OA varied according to type of setting: $39 \%$ in academic centres, $13 \%$ in the community hospitals and $54 \%$ in nonhospital settings (Figure 2).

Patient, physician and institution characteristics associated with receipt of OA colonoscopy in FY $2006(n=172,158)$ are summarized in Table 4. Patients 50 to 69 years of age (versus 70 years and older: OR 1.16 [95\% CI 1.06 to 1.23 ]; $\mathrm{P}<0.0001$ ) and those with the fewest comorbidities (versus greatest number of comorbidities: OR 2.92 [95\% CI 2.81 to 3.04 ]; $\mathrm{P}<0.0001$ ) were more likely to receive $\mathrm{OA}$ colonoscopy. Those in the highest income quintile were 1.28 times more likely to receive $\mathrm{OA}$ colonoscopy compared with those in the lowest income quintile (95\% CI 1.22 to 1.33 ; P<0.0001). Gastroenterologists were more likely to perform OA colonoscopy than surgeons (OR 1.8 [95\% CI 1.73 to 1.85$]$ ). The odds of receiving OA colonoscopy were 6.57 times greater in a nonhospital clinic than if the procedure was performed in a community hospital (95\% CI 6.32 to 6.75 ; $\mathrm{P}<0.0001)$.

\section{Study 2}

In the second cohort study, which evaluated the association between $\mathrm{OA}$ and incomplete colonoscopy, patients in the OA and non-OA groups were matched at a 1:1 ratio using propensity scores. Of the 41,976 patients who received OA colonoscopy in FY 2006, 29,767 were 
TABLE 2

Study 1: Patient and physician characteristics for openaccess (OA) and non-OA outpatient colonoscopy in Ontario, fiscal years 1997 to 2006

\begin{tabular}{|c|c|c|c|c|c|c|c|c|c|}
\hline \multirow[b]{2}{*}{ Patients } & \multicolumn{3}{|c|}{ Colonoscopy } & \multirow[b]{2}{*}{$\mathbf{P}$} & \multirow[b]{2}{*}{ Institution } & \multicolumn{3}{|c|}{ Colonoscopy } & \multirow[b]{2}{*}{$\mathbf{P}$} \\
\hline & $\begin{array}{c}\text { OA } \\
(n=216,413)\end{array}$ & $\begin{array}{c}\text { Non-OA } \\
(n=862,846)\end{array}$ & $\begin{array}{c}\text { Total } \\
(n=1,079,259)\end{array}$ & & & $\begin{array}{c}\text { OA } \\
(n=42,442)\end{array}$ & $\begin{array}{c}\text { non-OA } \\
(n=122,279)\end{array}$ & $\begin{array}{c}\text { Total } \\
(\mathrm{n}=164,721)\end{array}$ & \\
\hline Age, years, median & & & & $<0.0001$ & Type & & & & $<0.0001$ \\
\hline$<50$ & $60,610(28)$ & $287,143(33)$ & $347,753(32)$ & & Academic & $7,363(17)$ & $11,718(9)$ & $19,081(11)$ & \\
\hline $50-69$ & $125,313(58)$ & $424,876(49)$ & $550,189(51)$ & & Community & $14,054(32)$ & $92,410(72)$ & $106,464(62)$ & \\
\hline$\geq 70$ & 30,490 (14) & 150,807 (18) & 181,297 (17) & & Nonhospital & 21,025 (48) & $18,150(14)$ & $39,175(23)$ & \\
\hline Sex & & & & $<0.0001$ & Nonclassifiable & $1753(4)$ & $5684(4)$ & 7437 (4) & \\
\hline
\end{tabular}

Female $\quad 110,617(51) \quad 471,556(55) \quad 582,173(54)$

Male $\quad 105,796(49) \quad 391,290(45) \quad 497,086(46)$

Type of community

Rural $\quad 17,758(8) \quad 118,847(14) \quad 136,605(13)$

Urban $\quad 198,278(92) \quad 742,796(86) \quad 941,083(87)$

Local Health Integration Network (Ontario)

\begin{tabular}{lrrr} 
Erie St Clair & $4776(2)$ & $56,587(6.6)$ & $61,363(6)$ \\
South West & $17,815(8)$ & $56,327(6.5)$ & $74,142(7)$ \\
Waterloo Wellington & $3447(2)$ & $52,680(6.1)$ & $56,127(5)$ \\
Hamilton Niagara & $17,149(8)$ & $102,735(12)$ & $119,884(11)$ \\
Central West & $6550(3)$ & $45,085(5)$ & $51,635(5)$ \\
Mississauga Halton & $16,614(8)$ & $70,226(8)$ & $86,840(8)$ \\
Toronto Central & $44,561(21)$ & $73,467(9)$ & $118,028(11)$ \\
Central & $44,294(21)$ & $115,620(13)$ & $159,914(15)$ \\
Central East & $22,715(11)$ & $117,297(14)$ & $140,012(13)$ \\
Champlain & $17,700(8)$ & $77,781(9)$ & $95,481(9)$ \\
North Simcoe & $8654(4)$ & $38,761(5)$ & $47,415(4)$ \\
$\quad$ Muskoka & & & \\
North East & $11,965(6)$ & $55,786(7)$ & $67,751(6)$ \\
Income quintile & & & \\
Low & $26,293(12)$ & $126,768(15)$ & $153,061(14)$ \\
2 & $32,492(15)$ & $156,169(19)$ & $188,661(18)$ \\
3 & $37,139(18)$ & $169,879(20)$ & $207,018(19)$ \\
4 & $42,572(38)$ & $185,822(22)$ & $268,394(25)$ \\
High & $62,041(29)$ & $261,772(30)$ & $323,813(30)$ \\
Unknown & $40,161(19)$ & $211,180(25)$ & $251,341(23)$ \\
Comorbidity* (ADGs) & $31,639(15)$ & $204,072(24)$ & $235,711(22)$ \\
0-3 & & & \\
4-5 & & $185,425(22)$ & $229,661(21)$ \\
6-7 & & $19,095(2)$ & $23,960(2)$ \\
Physician & & & \\
\hline
\end{tabular}

Specialty

Gastroenterology $\quad 113,327(52) \quad 356,479(41) \quad 469,806(44)$

Surgery $\quad 82,136(38) \quad 415,079(48) \quad 497,215(46)$

Internal medicine $\quad 11,934(6) \quad 76,921(9) \quad 88,855(8)$

Other practitioner $^{\dagger} \quad 9,016(4) \quad 14,367$ (2) $\quad 23,383$ (2)

Physician volume quintile

$\begin{array}{llll}\text { Low } & 34,338(16) & 182,188(21) & 216,526(20) \\ 2 & 31,382(15) & 185,625(22) & 217,007(20) \\ 3 & 39,733(18) & 175,621(20) & 215,354(20) \\ 4 & 42,940(20) & 174,320(20) & 217,260(20) \\ \text { High } & 68,020(31) & 145,092(17) & 213,112(20)\end{array}$

Data presented as $n$ (\%) unless otherwise indicated. *Comorbidity scored using number of aggregated diagnosis groups (ADGs) using the Johns Hopkins Case Mix System; ${ }^{\dagger}$ Other practitioners comprise all other specialties including family physicians and general practitioners; ${ }^{\ddagger}$ Mean annual number of colonoscopies (using the average annual number of colonoscopies performed by the physician in the five years before the colonoscopy)
TABLE 3

Study 1: Institution characteristics for open access (OA) and non-OA outpatient colonoscopy in Ontario, fiscal year 2006

Data presented as $n$ (\%)

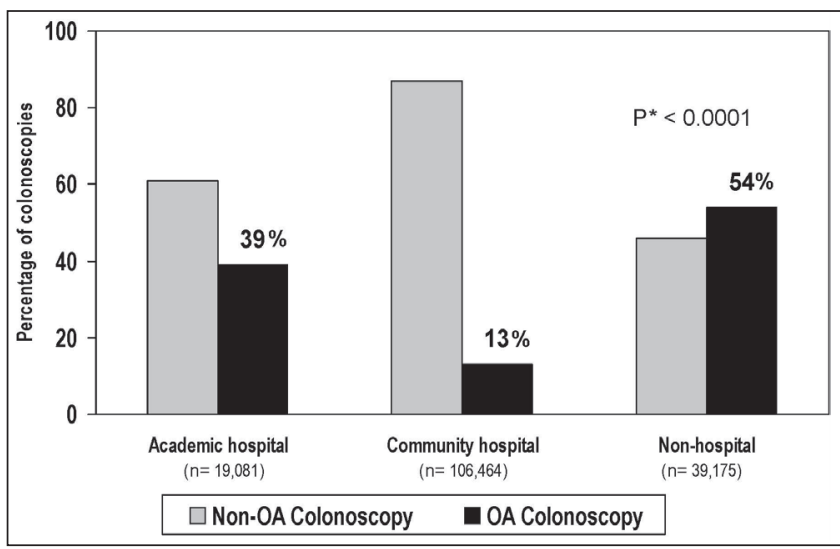

Figure 2) Proportion of open access (OA) and non-OA colonoscopies performed according to hospital type in Ontario, fiscal year 2006

included in the analysis (the remaining patients were excluded because there was no match in the non-OA group). Table 5 demonstrates that the matching was successful; the two groups were similar in terms of patient, physician and institution characteristics. The rates of incomplete colonoscopy were low in both groups: $5.3 \%$ in the OA group and $6.7 \%$ in the non-OA group. The proportion of patients with positive endoscopic findings (35\% of OA and $36 \%$ of non-OA colonoscopies) and in whom CRC was diagnosed ( $2 \%$ in each group) were similar between the two groups. Using conditional logistic regression analysis, it was determined that the odds of undergoing a complete colonoscopy was 1.3 times higher if the procedure was OA (95\% CI 1.2 to 1.4 ; $\mathrm{P}<0.0001)$.

Because facility type was a strong predictor of OA colonoscopy, it was included in the propensity score. However, a match for $>12,000$ patients could not be found, which threatened the generalizability of the findings. As a sensitivity analysis, the propensity score was recalculated without facility type and health region. Using this new propensity score, 39,564 OA colonoscopy patients could not be matched, leaving only 2412 (5.7\%) of OA colonoscopy patients unmatched. Other than facility type and health regions, the two groups were well-matched (data not shown). Using these two new groups, the odds of undergoing a complete colonoscopy did not change appreciably (OR 1.2 (95\% CI 1.2 to $1.3 ; \mathrm{P}<0.0001$ ) for $\mathrm{OA}$ versus non-OA colonoscopy).

\section{DISCUSSION}

We identified an important increase in the utilization of OA colonoscopy in Ontario between FY 1997 and FY 2006. In FY 2006, more than one-quarter of patients received colonoscopy in an $\mathrm{OA}$ fashion. Healthier patients in the target age group for screening as well as those living in higher-income neighbourhoods were more likely to receive OA colonoscopy. Most OA colonoscopy in Ontario is performed in nonhospital clinics. Our study also demonstrated that OA colonoscopy was more likely to be complete compared with non-OA colonoscopy. 
TABLE 4

Study 1: Multivariate logistic regression analysis of patient characteristics, physicians and institution setting associated with the use of open-access colonoscopy in Ontario, fiscal year $2006(n=172,158)$

\begin{tabular}{|c|c|c|}
\hline Patients & OR (95\% Cl) & $\mathbf{P}$ \\
\hline \multicolumn{3}{|l|}{ Age, years, median } \\
\hline$<50$ & $0.82(0.78-0.86)$ & $<0.0001$ \\
\hline $50-69$ & $1.16(1.06-1.23)$ & $<0.0001$ \\
\hline$\geq 70$ & $1(\mathrm{~N} / \mathrm{A})$ & N/A \\
\hline \multicolumn{3}{|l|}{ Sex } \\
\hline Female & $1.05(1.02-1.08)$ & 0.0002 \\
\hline Male & $1(\mathrm{~N} / \mathrm{A})$ & $\mathrm{N} / \mathrm{A}$ \\
\hline \multicolumn{3}{|l|}{ Income quintile } \\
\hline Low & $0.78(0.74-0.82)$ & $<0.0001$ \\
\hline 2 & $0.77(0.74-0.81)$ & $<0.0001$ \\
\hline 3 & $0.82(0.79-0.85)$ & $<0.0001$ \\
\hline 4 & $0.87(0.84-0.90)$ & $<0.0001$ \\
\hline High & $1(\mathrm{~N} / \mathrm{A})$ & $\mathrm{N} / \mathrm{A}$ \\
\hline \multicolumn{3}{|l|}{ Comorbidity* (ADGs) } \\
\hline $0-3$ & $2.92(2.81-3.04)$ & $<0.0001$ \\
\hline $4-5$ & $1.56(1.50-1.62)$ & $<0.0001$ \\
\hline $6-7$ & $1.05(1.00-1.09)$ & $<0.0001$ \\
\hline $8+$ & $1(\mathrm{~N} / \mathrm{A})$ & N/A \\
\hline \multicolumn{3}{|l|}{ Health region (Ontario) } \\
\hline Erie St Clair & $0.44(0.40-0.48)$ & $<0.0001$ \\
\hline South West & $1.10(1.04-1.17)$ & 0.0017 \\
\hline Waterloo Wellington & $0.27(0.25-0.30)$ & $<0.0001$ \\
\hline Hamilton Niagara & $0.49(0.46-0.52)$ & $<0.0001$ \\
\hline Central West & $0.50(0.47-0.54)$ & $<0.0001$ \\
\hline Mississauga Halton & $0.99(0.93-1.05)$ & 0.711 \\
\hline Toronto Central & $1.04(0.99-1.08)$ & 0.1383 \\
\hline Central & $0.73(0.69-0.77)$ & $<0.0001$ \\
\hline Central East & $0.38(0.36-0.40)$ & $<0.0001$ \\
\hline Champlain & $1.70(1.58-1.82)$ & $<0.0001$ \\
\hline North Simcoe Muskoka & $1.11(1.04-1.18)$ & 0.0027 \\
\hline North East & $1(\mathrm{~N} / \mathrm{A})$ & N/A \\
\hline \multicolumn{3}{|l|}{ Physician } \\
\hline \multicolumn{3}{|l|}{ Specialty } \\
\hline Gastroenterology & $1(N / A)$ & N/A \\
\hline Surgery & $0.56(0.54-0.58)$ & $<0.0001$ \\
\hline Internal medicine & $0.71(0.67-0.76)$ & $<0.0001$ \\
\hline Other practitioner ${ }^{\dagger}$ & $1.67(1.52-1.83)$ & $<0.0001$ \\
\hline \multicolumn{3}{|l|}{ Physician volume quintile } \\
\hline Low & $1.05(1.00-1.09)$ & 0.04 \\
\hline 2 & $0.80(0.76-0.83)$ & $<0.0001$ \\
\hline 3 & $0.78(0.75-0.82)$ & $<0.0001$ \\
\hline 4 & $0.76(0.73-0.79)$ & $<0.0001$ \\
\hline High & $1(\mathrm{~N} / \mathrm{A})$ & N/A \\
\hline \multicolumn{3}{|l|}{ Institution } \\
\hline \multicolumn{3}{|l|}{ Type } \\
\hline Academic & $0.61(0.58-0.64)$ & $<0.0001$ \\
\hline Community & $0.15(0.15-0.16)$ & $<0.0001$ \\
\hline Nonhospital & $1(\mathrm{~N} / \mathrm{A})$ & N/A \\
\hline
\end{tabular}

${ }^{*}$ Comorbidity scored using number of aggregated diagnosis groups (ADGs) using the Johns Hopkins Case Mix System; ${ }^{\dagger}$ Other practitioners comprise all other specialties including family physicians and general practitioners;

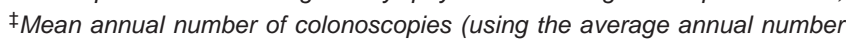
of colonoscopies performed by the physician in the five years before the colonoscopy). N/A Not applicable
TABLE 5

Study 2: Characteristics two patient cohorts (receiving open-access [OA] and non-OA colonoscopy in fiscal year 2006) matched according to propensity score

\begin{tabular}{|c|c|c|c|}
\hline \multirow[b]{2}{*}{ Patients } & \multicolumn{3}{|c|}{ Colonoscopy } \\
\hline & $\begin{array}{c}\text { OA } \\
(n=29,767)\end{array}$ & $\begin{array}{c}\text { Non-OA } \\
(n=29,767)\end{array}$ & $\begin{array}{c}\text { OA (not matched) } \\
(n=12,209)\end{array}$ \\
\hline \multicolumn{4}{|l|}{ Age, years, median } \\
\hline$<50$ & $7775(26)$ & $7775(26)$ & $2128(17)$ \\
\hline $50-69$ & $18,513(62)$ & $18,513(62)$ & $8676(71)$ \\
\hline$\geq 70$ & 3479 (12) & 3479 (12) & 1405 (12) \\
\hline \multicolumn{4}{|l|}{ Sex } \\
\hline Female & $15,559(52)$ & $15,559(52)$ & $6010(49)$ \\
\hline Male & $14,208(48)$ & $14,208(48)$ & $6199(51)$ \\
\hline \multicolumn{4}{|l|}{ Income quintile } \\
\hline Low & $3450(12)$ & 3615 (12) & $1363(11)$ \\
\hline 2 & 4469 (15) & $4574(15)$ & $1662(14)$ \\
\hline 3 & $5413(18)$ & $5362(18)$ & $2008(16)$ \\
\hline 4 & $7074(24)$ & $7096(24)$ & $2657(22)$ \\
\hline High & $9361(32)$ & $9120(31)$ & $4519(37)$ \\
\hline \multicolumn{4}{|c|}{ Comorbidities* (ADGs) } \\
\hline $0-3$ & $10,695(36)$ & $10,093(34)$ & $6286(51)$ \\
\hline $4-5$ & $9323(31)$ & $9487(32)$ & $3093(25)$ \\
\hline $6-7$ & 5544 (19) & $5843(20)$ & $1737(14)$ \\
\hline$\geq 8$ & 4205 (14) & $4344(15)$ & $1093(9)$ \\
\hline \multicolumn{4}{|l|}{ Physicians } \\
\hline \multicolumn{4}{|l|}{ Specialty } \\
\hline Gastroenterology & $15,465(52)$ & $16,870(57)$ & $5165(42)$ \\
\hline Surgery & $12,554(42)$ & $11,285(38)$ & $5538(45)$ \\
\hline Internal medicine & $1080(4)$ & $925(3)$ & $681(6)$ \\
\hline Other practitioner ${ }^{\dagger}$ & $668(2)$ & $687(2)$ & $825(7)$ \\
\hline \multicolumn{4}{|c|}{ Physician volume quintile ${ }^{\ddagger}$} \\
\hline Low & $5380(18)$ & 4917 (17) & $2803(23)$ \\
\hline 2 & $4523(15)$ & $4286(14)$ & $2156(18)$ \\
\hline 3 & $4825(16)$ & $4672(16)$ & $1822(15)$ \\
\hline 4 & $5932(20)$ & $6280(21)$ & $1763(14)$ \\
\hline High & 9107 (31) & $9612(32)$ & $3665(30)$ \\
\hline \multicolumn{4}{|l|}{ Institution } \\
\hline \multicolumn{4}{|l|}{ Type } \\
\hline Academic & $4899(17)$ & $5177(17)$ & 2318 (19) \\
\hline Community & $12,193(41)$ & $12,211(41)$ & $1961(16)$ \\
\hline Nonhospital & $12,675(43)$ & $12,379(42)$ & $7930(65)$ \\
\hline
\end{tabular}

Data presented as $n$ (\%). *Comorbidity scored using number of aggregated diagnosis groups (ADGs) using the Johns Hopkins Case-Mix System; ${ }^{\dagger}$ Other practitioners comprise all other specialties including family physicians and general practitioners; ${ }^{\ddagger}$ Mean annual number of colonoscopies (using the average annual number of colonoscopies performed by the physician in the five years before the colonoscopy)

To date, there have been no population-based studies evaluating the prevalence of OA colonoscopy in North America and Europe. Studies from the 1990s surveyed physicians and found that between $60 \%$ and $74 \%$ of respondents from the United States (3) and United Kingdom (20), respectively, offered some form of OA endoscopy; however, these studies were not designed to describe this practice at the patient or population level. Our study is the first to report on the practice of OA colonoscopy at the population level, and we identified an important change in the pattern of delivery of colonoscopy services in Ontario. The observed rise in OA colonoscopy may reflect the increasing use of colonoscopy for CRC screening, a hypothesis that is supported by our finding that individuals 50 to 69 years of age were more likely to receive OA colonoscopy. We anticipate that the use of OA colonoscopy will likely continue to rise as the demand for 
colonoscopy services continues to increase in Ontario, especially with the launch of Ontario's province-wide, organized CRC screening program, ColonCancerCheck (http://health.gov.on.ca/en/public/programs/coloncancercheck/). A second possible reason for rise in $\mathrm{OA}$ colonoscopy utilization may result from our finding that most $\mathrm{OA}$ colonoscopy was performed in nonhospital clinics. During the period of our study, there was significant growth in the number of such clinics in Ontario.

Demand for colonoscopy is anticipated to continue internationally as CRC screening becomes more widespread; in the United States, Medicare (www.medicare.gov/navigation/manage-your-health/preventive-services/colon-cancer-screening.aspx?AspxAutoDetectCooki eSupport $=1$ ) has covered screening colonoscopy since 2001, and many jurisdictions in North American and Europe have or will soon launch organized CRC screening programs (http://appliedresearch.cancer. gov/icsn/colorectal/screening.html). Furthermore, we found that healthier patients were more likely to undergo OA colonoscopy, which would be expected because patients with significant comorbidities should be seen by the endoscopist before the procedure. We anticipate that this finding is generalizable to other countries. Therefore, the trends (patient characterstics, increasing utilization of OA colonoscopy) we observed in Ontario likely reflect experiences in other jurisdictions.

Evaluation of the quality of OA colonoscopy is critical given its extensive use. Our results show that completion rates are higher in patients undergoing $\mathrm{OA}$ colonoscopies, thereby refuting our hypothesis that patients undergoing $\mathrm{OA}$ procedures would experience more incomplete procedures. Some reports indicate that patients undergoing $\mathrm{OA}$ endoscopic procedures are less likely to be properly informed about their procedure (8); insufficient information regarding the procedure could, in turn, adversely affect bowel preparation. Poor preparation adversely affects colonoscopy completion rates $(21,22)$, a well-recognized quality indicator. Nevertheless, our results, using population-based data, are highly reassuring given the increasing use of OA colonoscopy that we have demonstrated. Our findings are concordant with another large multinational, multisite study from Europe (21).

Our findings must be interpreted in light of the strengths and weaknesses of the study. Because we relied on administrative data, our study was limited to variables contained in these databases, and

\section{REFERENCES}

1. Eisen GM, Baron TH, Dominitz JA, et al. Open access endoscopy. Gastrointest Endosc 2002;56:793-5.

2. Bramble MG. Open access endoscopy - a nationwide survey of current practice. Gut 1992;33:282-5.

3. Mahajan RJ, Marshall JB. Prevalence of open-access gastrointestinal endoscopy in the United States. Gastrointest Endosc 1997;46:21-6.

4. Bersani G, Rossi A, Ricci G, et al. Do ASGE guidelines for the appropriate use of colonoscopy enhance the probability of finding relevant pathologies in an open access service? Dig Liver Dis 2005;37:609-14.

5. Mahajan RJ, Barthel JS, Marshall JB. Appropriateness of referrals for open-access endoscopy. How do physicians in different medical specialties do? Arch Intern Med 1996;156:2065-9.

6. Minoli G, Meucci G, Bortoli A, et al. The ASGE guidelines for the appropriate use of colonoscopy in an open access system. Gastrointest Endosc 2000;52:39-44.

7. Kisloff B, Peele PB, Sharam R, Slivka A. Quality of patient referral information for open-access endoscopic procedures. Gastrointest Endosc 2006;64:565-9.

8. Staff DM, Saeian K, Rochling F, et al. Does open access endoscopy close the door to an adequately informed patient? Gastrointest Endosc 2000;52:212-7.

9. Reid RJ, Roos NP, MacWilliam L, Frohlich N, Black C. Assessing population health care need using a claims-based ACG morbidity measure: A validation analysis in the Province of Manitoba. Health Serv Res 2002;37:1345-64.

10. Starfield B, Weiner J, Mumford L, Steinwachs D. Ambulatory care groups: A categorization of diagnoses for research and management. Health Serv Res 1991;26:53-74.

11. Weiner JP, Starfield BH, Steinwachs DM, Mumford LM. Development and application of a population-oriented measure of ambulatory care case-mix. Med Care 1991;29:452-72. important clinical data, such as the indication for the procedure or the quality of the bowel preparation, were not available to us. As a result, we could not distinguish which procedures were for screening; therefore, we cannot definitively exclude confounding by indication (22). Furthermore, we were not able to evaluate the association between OA colonoscopy and other important quality indicators, such as adenoma detection rate or patient satisfaction, and understanding of colonoscopy findings. Studies that use administrative data rely on accurate input from physicians to document the extent of the procedure. Although it is possible that we were identifying flexible sigmoidoscopy with the codes intended to define incomplete colonoscopy (ie, if a Z555 + E740 was billed), when we restricted our definition of incomplete colonoscopy to procedures reaching the hepatic flexure only $($ Z555 \pm E740 + E741), our results were unchanged. While we acknowledge these limitations resulting from the use of administrative data, these data allow us to study the entire population of Ontario. As such, we are able to describe 'usual clinical practice' and to reduce selection bias that can occur in single-centre studies or other convenience samples. Another concern was the failure to match almost onethird of the OA colonoscopy patients in study 2, threatening the generalizability of our findings. To address this, we performed a sensitivity analysis in which we were able to match $94 \%$ of the OA colonoscopy patients. The ORs for the association between OA colonoscopy and completeness remained similar to the initial analysis, indicating that our findings are robust and generalizable.

\section{CONCLUSION}

Our population-based study demonstrates that the use of OA colonoscopy is increasing in Ontario, occurring primarily in healthier patients in the target age group for screening and in those from higher-income neighbourhoods. Colonoscopy completeness, a recognized colonoscopy quality indicator, does not appear to be compromised by the use of OA colonoscopy.

ACKNOWLEDGEMENTS: Dr Tinmouth holds a CIHR New Investigator Salary Award. The authors acknowledge the support of the Institutes for Clinical Evaluative Sciences, the Ontario Ministry of Health and Long-Term Care and Cancer Care Ontario.

12. Cleves MA, Sanchez N, Draheim M. Evaluation of two competing methods for calculating Charlson's comorbidity index when analyzing short-term mortality using administrative data. J Clin Epidemiol 1997;50:903-8.

13. Alter DA, Naylor DC, Austin P, Tu JV. Effects of socioeconomic status on access to invasive cardiac procedures and on mortality after acute myocardial infarction. N Engl J Med 1999;341:1359-67.

14. Singh SM, Paszat LF, Li C, et al. Association of socioeconomic status and receipt of colorectal cancer investigations: A populationbased retrospective cohort study. CMAJ 2004;171:461-5.

15. Alharbi O, Rabeneck L, Paszat LF, et al. A population-based analysis of outpatient colonoscopy in adults assisted by an anesthesiologist. J Anesthesiology 2009;111:734-40.

16. Bressler B, Paszat LF, Chen Z, et al. Rates of new or missed colorectal cancers after colonoscopy and their risk factors: A population-based analysis. Gastroenterology 2007;132:96-102.

17. R Development Core Team. R: A Language and Environment for Statistical Computing. R Foundation for Statistical Computing, Vienna, Austria, 2009.

18. Austin PC. The performance of different propensity-score methods for estimating relative risks. J Clin Epidemiol 2008;61:537-45.

19. D'Agostino RBJ. Propensity score methods for bias reduction in the comparison of a treatment to a non-randomized control group. Stat Med 1998;17:2265-81.

20. Silcock JG, Bramble MG. Open access gastroscopy: Second survey of current practice in the United Kingdom. Gut 1997;40:192-5.

21. Harris JK, Froehlich F, Wietlisbach V, et al. Factors associated with the technical performance of colonoscopy: An EPAGE Study. Dig Liver Dis 2007;39:678-89.

22. Hully SB, Cummings SR, Browner WS, Grady DG, Newman TB. Designing Clinical Research, 3rd edn. Philadephia: Lippincott, Williams and Wilkins; 2007. 


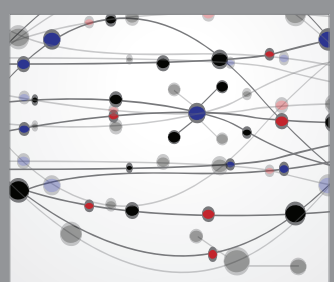

The Scientific World Journal
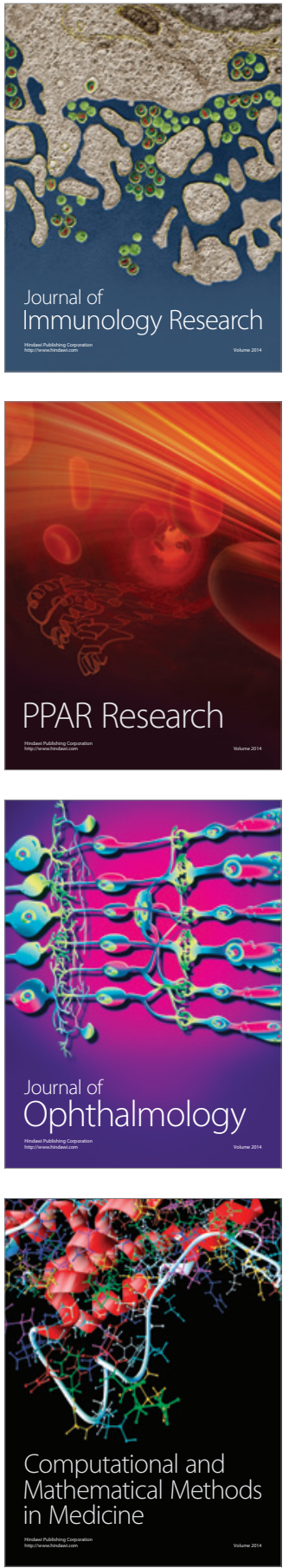

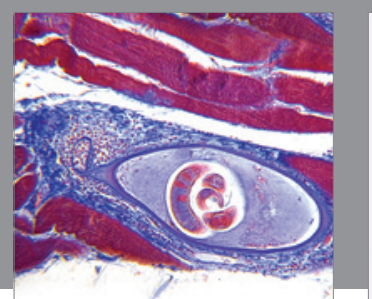

Gastroenterology Research and Practice

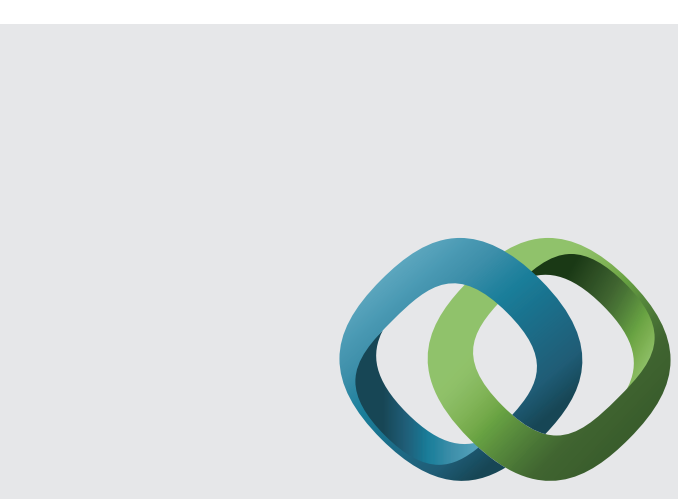

\section{Hindawi}

Submit your manuscripts at

http://www.hindawi.com
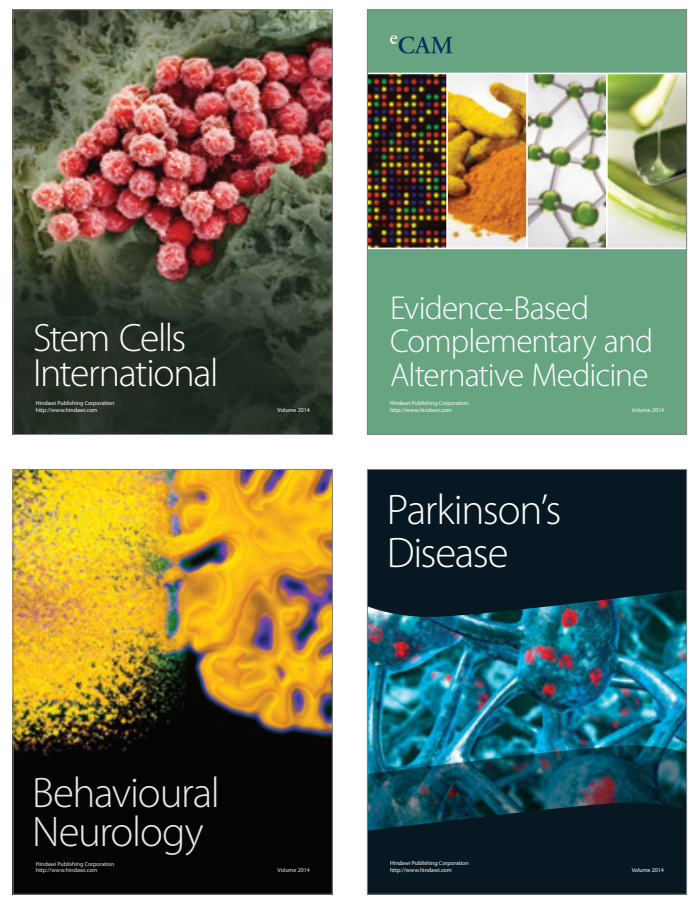
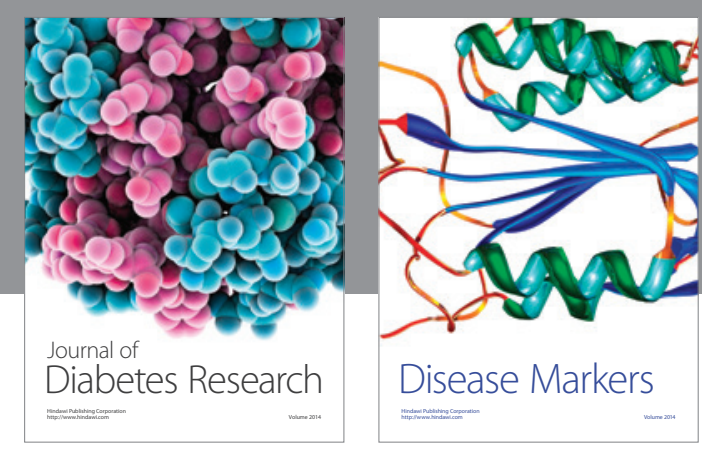

Disease Markers
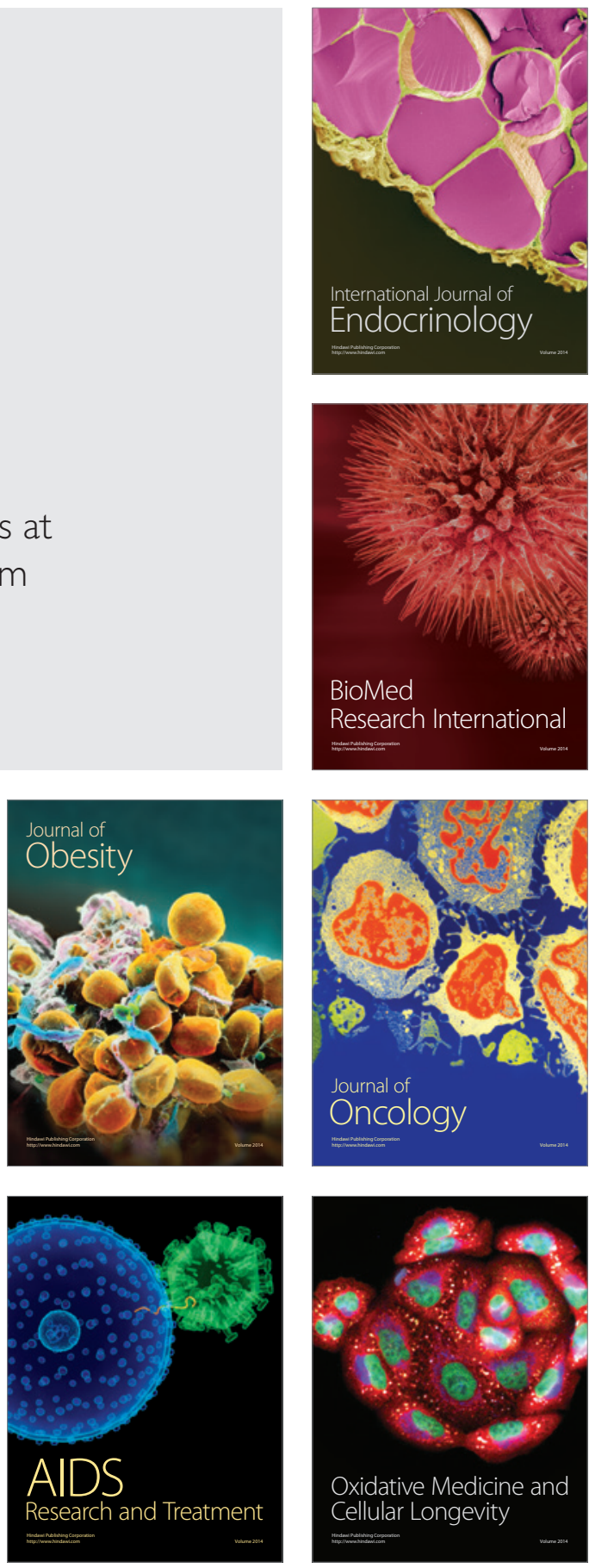